\title{
An Ultra-sensitive and selective LC-UV method for the simultaneous determination of pravastatin, diltiazem, naproxen sodium and meloxicam in API, pharmaceutical formulations and human serum
}

\author{
Najma Sultana ${ }^{1}$, Muhammad Saeed Arayne ${ }^{2}$, Saeeda Nadir Ali ${ }^{2, *}$ \\ ${ }^{1}$ Department of Pharmaceutical Chemistry, University of Karachi, Karachi-75270, Pakistan \\ ${ }^{2}$ Department of Chemistry, University of Karachi, Karachi-75270, Pakistan
}

Email address:

saeeda_khowaja@hotmail.com (S. Nadir Ali)

\section{To cite this article:}

Najma Sultana, Muhammad Saeed Arayne, Saeeda Nadir Ali. An Ultra-Sensitive and Selective LC-UV Method for the Simultaneous Determination of Pravastatin, Diltiazem, Naproxen Sodium and Meloxicam in API, Pharmaceutical Formulations and Human Serum . American Journal of Applied Chemistry. Vol. 1, No. 1, 2013, pp. 1-8. doi: 10.11648/j.ajac.20130101.11

\begin{abstract}
The aim of the present work was to develop a sensitive liquid chromatographic method for the quantitation of pravastatin and diltiazem along with naproxen and meloxicam using ultraviolet detector. The separation of components was achieved on Purospher Star, $\mathrm{C}_{18}(5 \mu \mathrm{m}, 25 \mathrm{x} 0.46 \mathrm{~cm})$ column using methanol-water $(80: 20 \mathrm{v} / \mathrm{v})$ as mobile phase and $\mathrm{pH}$ adjusted 3.4 with $85 \% o$-phosphoric acid. Related parameters that may influence the enrichment efficiency of speration of drugs such as the kind and volume of elute, sample flow rate, sample $\mathrm{pH}$, and volume of the drug samples were investigated. Detection was performed at ambient temperature at $220 \mathrm{~nm}$ by pumping the mobile phase at the flow rate $1.0 \mathrm{~mL} \mathrm{~min}^{-1}$. The experimental results indicated a good linearity $\left(\mathrm{R}^{2}>0.9947\right)$ over the concentration range of $0.5-20 \mu \mathrm{g} \mathrm{mL}$ for pravastatin, naproxen and meloxicam and $0.75-24 \mu \mathrm{g} \mathrm{mL}^{-1}$ for diltiazem. The method was compared by programming the detector adjusting the wavelength with time to match the individual analyte's chromophore which enhanced sensitivity with linear range $0.25-8.0,0.5-16,0.4-12$ and $0.2-4.0 \mu \mathrm{g} \mathrm{mL}^{-1}$ for pravastatin, diltiazem, naproxen and meloxicam respectively. The LOD values shifted down from 33, 70, 50 and $80 \mathrm{ng} \mathrm{mL}^{-1}$ to $15,42,20$ and $10 \mathrm{ng} \mathrm{mL}^{-1}$ for pravastatin, diltiazem, naproxen and meloxicam respectively. Validation of the method showed good precision and accuracy for the proposed method. All the results indicated that this procedure could allow the simultaneous determination of these four compounds in API, pharmaceutical formulations and serum at trace levels. The method can be successfully applied for the determination of these drugs in human serum, clinical laboratories and in pharmaceutical formulations without diode array detector and without interference of excipients or endogenous components of serum.
\end{abstract}

Keywords: Pravastatin, Diltiazem, Naproxen, Meloxicam, RP-HPLC, Time Program

\section{Introduction}

Pravastatin (PRA) (figure.1: I) is a potent statin which averts the cholesterol production in the liver by blocking the enzyme HMG-CoA reductase that produces cholesterol. It shows significant protection against cisplatin-induced nephrotoxicity in mice [1] and also found to reduce edema in spontaneously hypertensive rats when administered intravenously after middle cerebral artery occlusion [2]. Diltiazem hydrochloride (DTZ) ((figure.1: II) is a non dihydropyridine calcium channel blocker antagonist, frequently used as antihypertensive [3] and possesses antianginal and antiarrythmic properties [4]. Non-steroidal an- ti-inflammatory drugs (NSAIDs) are widely prescribed for the treatment of inflammatory conditions such as rheumatoid arthritis, osteoarthritis and ankylosing spondilytis [5]. They are known to relief symptoms of primary dysmenorrhea, fever and also possess mild antiplatelet effect. They are useful in sepsis-induced acute pneumonia [6], in retarding metastases of mammary carcinoma [7] and in preventing oxidative lesions of lungs caused by phosgene [8]. Naproxen (NAP) (figure.1: III) and meloxicam (MEL) (figure.1: IV), are potent inhibitors of cyclooxygenase enzyme are novel NSAIDs of aryl acetic acid group and oxicam class respectively.

Literature review reveals that a number of analytical 
methods have been reported for the determination of these drugs in pharmaceutical formulations, human serum and body fluids by using different analytical techniques. PRA has been determined by capillary electrophoretic method [9], liquid chromatography [10], gas chromatography employing chemical ionization mass spectrometry (GC/CIMS) [11], HPTLC [12] and enzyme immunoassay [13]. Reported methods for the determination of DTZ and its metabolites include spectrophotometry [14], amperometry [15], HPLC [16], HPTLC [17], capillary gas chromatography [18] and liquid-liquid micro-extraction [19]. Different techniques have been reported for the determination of NAP i.e. chip-based immunoaffinity capillary electrophoresis [20], HPLC [21], HPTLC [22], LC-MS/MS [23] and GC/MS [24]. For the determination of MEL, spectrophotometric [25], Voltammetric [26], fluorimetric [27], electrochemical [28], HPLC [29] and capillary electrophoresis [30] are reported. A number of methods for individual or simultaneous determination of these and many other [31-33] drugs have also been developed by our research group like liquid chromatographic method for simultaneous determination of ceftriaxone sodium [34] with statin, lisinopril with statin [35] and NSAIDs [36], NSAID with statin [37, 38], DTZ with non steroidal anti-inflammatory drugs [39], MEL [40], , NAP [41].
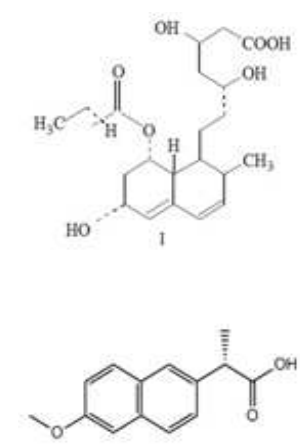

III
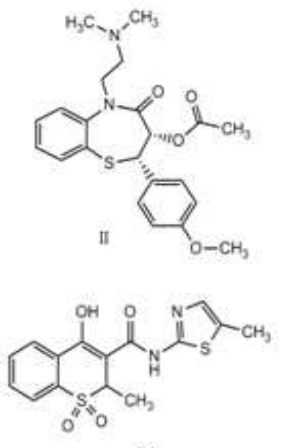

IV
Fig. 1. Chemical structures

Present study describes a rapid, ultra-sensitive liquid chromatographic method for the simultaneous determination of PRA, DTZ, NAP and MEL. The developed method has many advantages; being low cost without using expensive reagents and chemicals. Diode array detector has since long been used to enhance the sensitivity of such methods but the method presented is viable giving ultra sensitivity in simultaneous separation of representatives of statins (PRA), calcium channel blockers (DTZ) and NSAIDs (NAP and MEL) in API, pharmaceutical formulation and human serum, without diode array detector. The method employs adjusting the wavelength with time to match the individual analyte's absorption maxima. As a result the method is extremely low cost and can be adopted easily. The method has been validated following the ICH guidelines [42] at isosbestic point of $220 \mathrm{~nm}$ and by programming the detector adjusting the wavelength with time to match the individual analyte's chromophore to enhance the sensitivity of each component. It can successfully be applied for the determination of these drugs with good percent recovery in human serum and pharmaceutical formulation with out any chromatographic interference from tablet excipients or serum.

\section{Experimental}

\section{1. . Standards and Reagents}

PRA (Bristol Meyer Squib), DTZ (Abbott Laboratories Pvt Ltd), NAP (PharmEvo Pvt Ltd) and MEL (AGP Pharma Pvt Ltd) were used as reference standards. Pravachol ${ }^{\circledR}(20$ $\mathrm{mg})$, Calcard $\AA(60 \mathrm{mg})$, Anex ${ }^{\circledR}(275 \mathrm{mg})$ and Melfax ${ }^{\circledR}$ $(15 \mathrm{mg})$ were purchased from local pharmacy. HPLC grade methanol, 85\% o-phosphoric acid (Merck Darmstadt, Germany) and double distilled de-ionized water were used throughout the analysis. Drug free human serum was voluntarily donated by healthy person and collected at Fatmid Foundation Karachi.

\subsection{Instrumentation}

All chromatographic experiments were carried out using HPLC system consisting of Shimadzu LC-20 AT VP solvent delivery pump, rheodyne manual injector fitted with a $20 \mu \mathrm{L}$ loop and a SPD-20A Shimadzu UV visible detector. Chromatographic separation was performed by using a $\mathrm{Pu}-$ rospher Star, C18 $(5 \mu \mathrm{m}, 25 \times 0.46 \mathrm{~cm})$ column. Another column of same specification Discovery, C18 (5 $\mu \mathrm{m}, 25 \mathrm{x}$ $0.46 \mathrm{~cm}$ ) was used for ruggedness studies. Shimadzu CBM-102 communication Bus Module was used for data integration. Data acquisition was performed by Shimadzu Class-GC 10 software (version 2). Shimadzu 1800 UV-visible spectrophotometer was used for the determination of individual $\lambda$ max and isosbestic point of drug analytes.

\subsection{HPLC Conditions and Method Optimization}

A number of initial chromatographic parameters including different ratios of mobile phase, $\mathrm{pH}$, and flow rates were evaluated to achieve the best resolution with shortest retention time and good separation of components. The suitable mobile phase consisted of methanol-water (80:20 $\mathrm{v} / \mathrm{v}$ ) adjusted to $\mathrm{pH} 3.4$ with o-phosphoric acid (85\%). Prior to delivering into the system it was filtered through a millipore vacuum filter system equipped with $0.45 \mu \mathrm{m}$ filter and degassed using an ultrasonic bath (LC 30H). All the raw materials were eluted isocratically with a flow rate of $1.0 \mathrm{~mL} \mathrm{min-1}$ at room temperature. Initially, the spectrophotometric detector was operated at $220 \mathrm{~nm}$ and then comparative studies were carried out by programming the detector at 237, 240, 230 and $205 \mathrm{~nm}$ for PRA, DTZ, NAP and MEL respectively.

\subsection{Preparation of Solutions and Calibration Curves}

Stock solution of $50 \mu \mathrm{gmL}-1$ of all reference standards were prepared in methanol:water 80:20 (diluent). Each so- 
lution was sequentially diluted to working standard solutions of $0.5-20 \mu \mathrm{gmL}-1$ for PRA, NAP and MEL and 0.75-24 $\mu$ gmL-1 for DTZ for isosbestic point and 0.25-8.0, $0.5-16,0.4-12$ and $0.2-4.0 \mu \mathrm{g} \mathrm{mL}-1$ for PRA, DTZ, NAP and MEL for time program respectively with diluent for the preparation of calibration curves. These working standard solutions were prepared once and stored at $-20 \mathrm{oC}$, and analyzed daily for interday and intraday precision of the method. $20 \mu \mathrm{L}$ of these solutions was injected into the $\mathrm{LC}$ system. Before injecting into the system all the solutions were degassed by a sonicator and then filtered through a $0.45 \mu \mathrm{m}$ filter.

\subsection{Sample preparation}

\subsubsection{Pharmaceutical Preparations}

Twenty tablets of each sample, Pravachol ${ }^{\circledR}(20 \mathrm{mg})$, Calcard $\AA$ (60 mg), Anex ${ }^{\circledR}(275 \mathrm{mg})$ and Melfax ${ }^{\circledR}(15 \mathrm{mg})$, were individually triturated to obtain homogenous mixture. The amount equivalent to $10 \mathrm{mg}$ of sample was transferred into $100 \mathrm{~mL}$ volumetric flasks separately and dissolved in diluent. The resulting solutions were sonicated to facilitate proper solubilization. These solutions were then filtered to separate insoluble excipients and the volume of each flask was completed with diluent. All the solutions were diluted to get the final concentration of $50 \mu \mathrm{g} \mathrm{mL}-1$. Each solution was serially diluted to $0.5-20 \mu \mathrm{gmL}-1$ for PRA, NAP and MEL and $0.75-24 \mu \mathrm{g} \mathrm{mL}-1$ for DTZ for isosbestic point and $0.25-8.0,0.5-16,0.4-12$ and $0.2-4.0 \mu \mathrm{g} \mathrm{mL}-1$ for PRA, DTZ, NAP and MEL for time program respectively.

\subsubsection{Drug Serum Solutions}

Into $1.0 \mathrm{~mL}$ of plasma, $9 \mathrm{~mL}$ of acetonitrile was added and vortexed for one minute and followed by centrifugation for 10 minutes at $10,000 \mathrm{rpm}$. The resultant deproteinated supernatant was filtered by a $0.45 \mu$ membrane filter. The clear solution obtained was spiked with drug solutions to produce desired concentrations of PRA, DTZ, NAP and MEL in human serum. $20 \mu \mathrm{L}$ of these solutions was injected into the LC system. The prepared serum solutions were stored at $-20 \mathrm{oC}$.

\subsection{Method Validation}

Following ICH guidelines [38], the developed analytical method was validated to be efficient for the analysis of studied drugs in bulk drug and in human serum employing various parameters including system suitability test, linearity, accuracy, precision, specificity, limits of detection and quantitation, robustness and ruggedness.

\subsubsection{Specificity}

Specificity of the proposed method was analyzed through possible interference due to commonly present excipient or endogenous components of serum. For this purpose, placebo (without active) of each tablet was prepared in mobile phase. The excipients include starch, carboxymethylcellulose, magnesium stearate, monohydrated lactose and neutral talc. Placebo, blank serum, tablet sam- ple and spiked serum sample were injected to the system.

\subsubsection{System Suitability}

The system suitability of the method was accessed by equilibrating the initial mobile phase composition, followed by ten consecutive injections of same standard. The system suitability was evaluated on each day of method validation.

\subsubsection{Linearity}

Aliquots of stock standard solutions of PRA, DTZ, NAP and MEL were transferred in to two different series of 25 $\mathrm{mL}$ volumetric flasks to get the concentration of $0.5-20 \mu \mathrm{g}$ mL-1 for PRA, NAP and MEL and $0.75-24 \mu \mathrm{gmL}-1$ for DTZ for isosbestic point and 0.25-8.0, 0.5-16, 0.4-12 and 0.2-4.0 $\mu \mathrm{g} \mathrm{mL-1} \mathrm{for} \mathrm{PRA,} \mathrm{DTZ,} \mathrm{NAP} \mathrm{and} \mathrm{MEL} \mathrm{for} \mathrm{time}$ program respectively and the volumes were made up to the mark with 80:20 methanol-water (diluent). Calibration curves were constructed to evaluate linearity.

\subsubsection{Precision}

The intra-day precision of the method was evaluated at six concentration levels ranging from $0.5-20 \mu \mathrm{g} \mathrm{mL}-1$ for PRA, NAP and MEL and 0.75-24 $\mu$ gmL-1 for DTZ at isosbestic point and $0.25-8.0,0.5-16,0.4-12$ and $0.2-4.0 \mu \mathrm{g}$ mL-1 of PRA, DTZ, NAP and MEL for time program respectively. The inter-day precision was assessed at three consecutive days. Similarly, intra-day and inter-day precision in serum was evaluated at 2.5, 5.0 and $10 \mu \mathrm{g} \mathrm{mL}-1$ for PRA, NAP and MEL and 3.0, 6.0 and $12.0 \mu \mathrm{g} \mathrm{mL}-1$ for DTZ respectively.

\subsubsection{Accuracy}

Aliquots of standard tablet solutions and serum sample were transferred into $25 \mathrm{~mL}$ volumetric flasks and final volumes were completed with mobile phase. The final concentrations of each series were 2.5, 5.0 and $10 \mu \mathrm{g} \mathrm{mL}-1$ for PRA, NAP and MEL and 3.0, 6.0 and 12.0 $\mu \mathrm{g} \mathrm{mL-1} \mathrm{for}$ DTZ respectively and percent recovery was calculated.

\subsubsection{Detection and Quantitation Limits}

The detection and quantitation limits were calculated from slope and standard deviation of calibration curve by employing equation $\mathrm{LOD}=3.3 \mathrm{SD} / \alpha$ and $\mathrm{LOQ}=10 \mathrm{SD} /$ $\alpha$ respectively, where SD is the standard deviation and $\alpha$ is the slope of curve.

\subsubsection{Ruggedness}

The ruggedness of the method was evaluated on two different columns of same specification Discovery, C18 $(5 \mu \mathrm{m}$, $25 \times 0.46 \mathrm{~cm})$ and Purospher STAR, C18 (5 $\mu \mathrm{m}, 25 \times 0.46$ $\mathrm{cm})$ while taking all other parameters constant including mobile phase, $\mathrm{pH}$, flow rate and wavelength of detector. The analysis was carried out in the same lab and on the same instrument.

\subsubsection{Robustness}

The optimum parameters were varied like mobile phase ratio 80:20 methanol water $\pm 2.0, \mathrm{pH} 3.4 \pm 0.2$, flow rate $1.0 \pm 0.1 \mathrm{~mL}$ min-1 and detector wavelength $220 \pm 2.0 \mathrm{~nm}$ 
at fixed concentration of $2.5 \mu \mathrm{gmL}-1$ for PRA, NAP and MEL and $3.0 \mu \mathrm{gmL}-1$ for DTZ to assess the robustness of the method by six replicate analyses.

\section{3.. Results and Discussion}

\subsection{Method Development and Optimization}

The use of statin and calcium channel blocker with NSAIDs demands the need of simultaneous determination of these drugs in human serum and dosage forms as no method has yet been developed. Consequently, the aim of present study was to develop a rapid, sensitive, consistent and least expensive liquid chromatographic method for the simultaneous analysis of PRA, DTZ, NAP and MEL in bulk drug, human serum and in pharmaceutical formulations. The present work reports a sensitive high-performance liquid chromatographic method for the quantitation of the PRA and DTZ along with NAP and MEL with ultraviolet detection. The optimum parameters were investigated and developed method was validated.

The analysis was carried out at isosbestic point as well as by programming the detector. The chromatographic parameters were initially evaluated by varying the mobile phase compositions, $\mathrm{pH}$ and flow rate. Different ratios of methanol-water (80:20, 70:30, 60:40, and 50:50) with $\mathrm{pH}$ range 2.8-3.6 were investigated. Asymmetric peaks were obtained with greater tailing factor. The methanol-water $(80: 20 \mathrm{v} / \mathrm{v})$ with $\mathrm{pH} 3.4$ adjusted with $85 \%$ o-phosphoric acid at flow rate $1.0 \mathrm{~mL}$ min-1 resulted in symmetric peaks with good resolution and tailing factor with in acceptable limit. The UV scan showed absorbance maxima at 237, 240, 230 and $205 \mathrm{~nm}$ for PRA, DTZ, NAP and MEL respectively, therefore the detector wavelength was adjusted to $220 \mathrm{~nm}$ for analysis at isosbestic point where as the detector was programmed at individual wavelength for time program method. UV spectra and typical chromatogram showing the peaks of PRA, DTZ, NAP and MEL at isosbestic point as well as at time program method are represented in figures 2 and 3 .

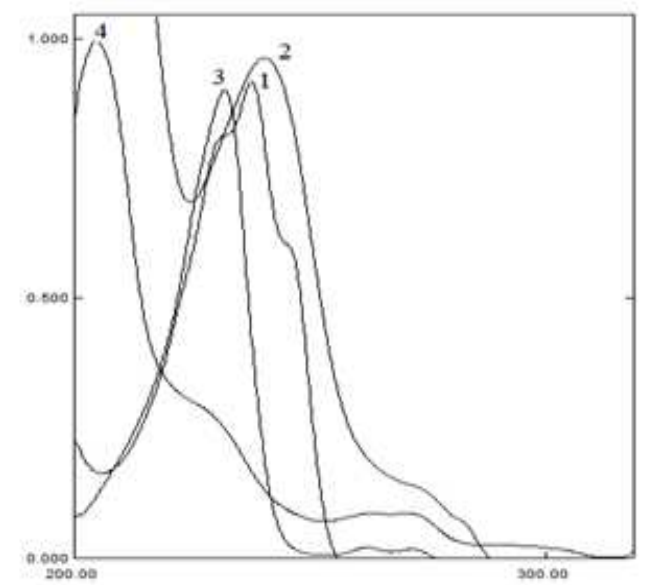

Fig. 2. Absorption spectra of (1) PRA, (2) DTZ (3) NAP and (4) MEL

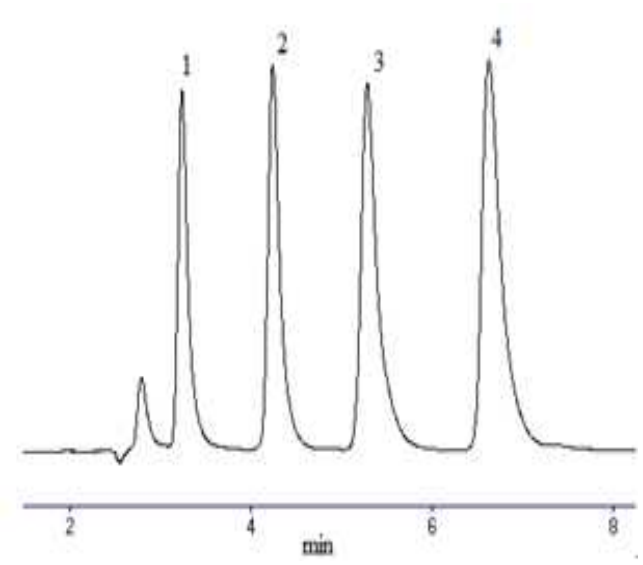

Fig. 3. Representative chromatogram of (1) PRA,(2) DTZ (3) NAP and (4) $M E L$

\subsection{Method Validation}

The developed method is rapid and sensitive and the analysis is complete within 7.5 minutes. The parameters employed to certify the validity of developed analytical method were suitability test, linearity, accuracy, precision, specificity, limits of detection and quantitation, robustness and ruggedness.

\subsubsection{Specificity}

Blank and spiked excipients and serum samples were analyzed to evaluate the specificity of the method and check the possible interference of excipients or endogenous components of serum. The chromatogram represented in figure 4 shows satisfactory peaks of components and confirms no interfering peaks of excipient or serum at the retention times for PRA, DTZ, NAP and MEL.

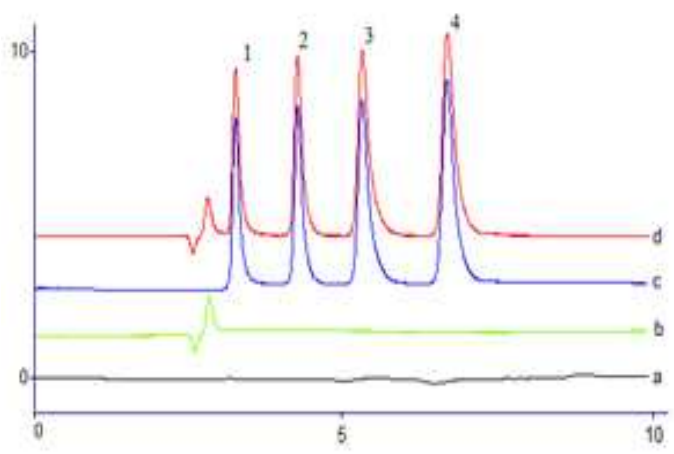

Fig. 4. Chromatograms of (a) solvent, (b) blank serum, (c) reference standard and (d) serum sample spiked with standards for (1) PRA, (2) DTZ (3) NAP and (4) MEL.

\subsubsection{System Suitability Test}

The \%RSD of all the drugs was found to be less than 2 indicating the suitability of the system. Moreover, the system suitability parameters including number of theoretical plates $(>2000)$ and tailing factor $(<2)$ for ten consecutive injections were found to be in the range. The system suitability data is presented in table 1 . 
Table 1. System suitability Parameters

\begin{tabular}{|c|c|c|c|c|c|c|}
\hline Drug & $t_{R}$ & $k^{\prime}$ & $\mathbf{N}$ & $\mathbf{T}$ & Res & $\mathbf{A}$ \\
\hline \multicolumn{7}{|c|}{ Isosbestic point } \\
\hline PRA & 3.22 & 0.66 & 4181 & 1.84 & 2.10 & 1.54 \\
\hline DTZ & 4.22 & 1.17 & 5252 & 1.69 & 4.64 & 1.79 \\
\hline NAP & 5.27 & 1.71 & 4738 & 1.83 & 3.87 & 1.46 \\
\hline MEL & 6.61 & 2.40 & 5098 & 1.90 & 3.97 & 1.40 \\
\hline \multicolumn{7}{|c|}{ Time program } \\
\hline PRA & 3.20 & 0.97 & 4325 & 1.62 & 2.22 & 1.39 \\
\hline DTZ & 4.24 & 1.59 & 5356 & 1.56 & 4.75 & 1.64 \\
\hline NAP & 5.30 & 2.24 & 4791 & 1.71 & 3.92 & 1.41 \\
\hline MEL & 6.66 & 3.07 & 5290 & 1.62 & 4.05 & 1.37 \\
\hline
\end{tabular}

$t_{R}=$ retention times, $k^{\prime}=$ capacity factor, $N=$ theoretical plates, $T=$ tailing factor, Res=resolution, $\alpha=$ separation factor

\subsubsection{Linearity}

Calibration curves were constructed with six different concentrations in the range of $0.5-20 \mu \mathrm{g} \mathrm{mL}-1$ for PRA, NAP and MEL and $0.75-24 \mu \mathrm{g} \mathrm{mL-1}$ for DTZ at isosbestic point. The correlation coefficients determined between peak area and concentration of drugs in each case were greater than 0.998 . The regression characteristics including slope, intercept, standard error and standard error of estimate are tabulated in table 2.

Table 2. Regression characteristics and sensitivity of the method

\begin{tabular}{|c|c|c|c|c|c|c|c|c|}
\hline Drug & $\begin{array}{c}\text { Linearity } \\
\mu_{\text {gmL }}{ }^{-1}\end{array}$ & Intercept & Slope & $\mathbf{R}^{2}$ & $\mathbf{S E}^{\mathbf{a}}$ & $\mathbf{S E E}^{\mathbf{b}}$ & $\begin{array}{c}\text { LOD } \\
\text { ngmL }^{-1} \\
\end{array}$ & $\begin{array}{c}\text { LOQ } \\
\text { ngmL }^{-1} \\
\end{array}$ \\
\hline \multicolumn{9}{|c|}{ Isosbestic point } \\
\hline PRA & $0.5-20$ & 24767 & 10416 & 0.9993 & 0.1647 & 0.2433 & 33 & 100 \\
\hline DTZ & $0.75-24$ & 23910 & 10762 & 0.9980 & 0.2895 & 0.4447 & 70 & 220 \\
\hline NAP & $0.5-20$ & 27256 & 16358 & 0.9996 & 0.1054 & 0.1641 & 50 & 140 \\
\hline MEL & $0.5-20$ & 28040 & 20627 & 0.9981 & 0.2293 & 0.3682 & 80 & 230 \\
\hline \multicolumn{9}{|c|}{ Time program } \\
\hline PRA & $0.25-8.0$ & 65866 & 53986 & 0.9986 & 1.0260 & 1.4798 & 15 & 46 \\
\hline DTZ & $0.5-16$ & 65552 & 33788 & 0.9997 & 1.2155 & 1.8185 & 42 & 128 \\
\hline NAP & $0.40-12$ & 133113 & 52484 & 0.9980 & 0.8406 & 1.2332 & 20 & 70 \\
\hline MEL & $0.2-4.0$ & 58881 & 188793 & 0.9981 & 0.1076 & 0.1740 & 10 & 20 \\
\hline \multicolumn{9}{|l|}{ Serum } \\
\hline PRA & - & 14864 & 13007 & 1.0000 & 0.2293 & 0.3682 & 60 & 180 \\
\hline DTZ & - & 17962 & 11898 & 0.9989 & 0.3674 & 0.2496 & 90 & 270 \\
\hline NAP & - & 30659 & 16107 & 1.0000 & 0.0349 & 0.0226 & 70 & 210 \\
\hline MEL & - & 35352 & 18763 & 0.9979 & 0.5333 & 0.3466 & 150 & 440 \\
\hline
\end{tabular}

$a=$ standard error estimate, $b=$ standard error

\subsubsection{Precision}

Precision of the proposed method was analyzed with respect to repeatability (intra-day) and intermediate (inter-day) precision over a period of three days for bulk drug and human serum, and was expressed as percent relative standard deviation. The \%RSD values for PRA, DTZ, NAP and MEL were found to be $0.14-1.95,0.52-1.90,0.13-1.98$ and $0.16-1.80$ at isosbestic point respectively assuring that the proposed method has high precision (table 3 ).

Table 3. Precision of the proposed method

\begin{tabular}{|c|c|c|c|c|c|c|c|}
\hline Conc & $\%$ RSD & Conc & $\%$ RSD & Conc & $\%$ RSD & Conc & $\%$ RSD \\
\hline$\overline{\text { PRA }}$ & & DTZ & & NAP & & Mel & \\
\hline \multicolumn{8}{|c|}{ Isosbestic point } \\
\hline 0.5 & 0.46 & 0.75 & 0.84 & 0.5 & 1.38 & 0.5 & 1.38 \\
\hline 1.25 & 1.80 & 1.5 & 1.90 & 1.25 & 0.13 & 1.25 & 0.33 \\
\hline 2.5 & 0.14 & 3 & 1.23 & 2.5 & 1.42 & 2.5 & 1.11 \\
\hline 5 & 1.19 & 6 & 0.54 & 5 & 1.21 & 5 & 1.80 \\
\hline 10 & 1.95 & 12 & 0.52 & 10 & 1.98 & 10 & 1.31 \\
\hline 20 & 0.29 & 24 & 0.62 & 20 & 0.43 & 20 & 0.16 \\
\hline \multicolumn{8}{|c|}{ Time program } \\
\hline 0.25 & 0.75 & 0.5 & 1.02 & 0.4 & 0.67 & 0.15 & 1.00 \\
\hline 0.5 & 0.29 & 1.0 & 0.95 & 0.8 & 0.94 & 0.25 & 0.79 \\
\hline 1.0 & 0.41 & 2.0 & 0.39 & 1.5 & 0.20 & 0.5 & 0.25 \\
\hline 2.0 & 0.14 & 4.0 & 0.69 & 3.0 & 0.27 & 1.0 & 0.16 \\
\hline 4.0 & 0.08 & 8.0 & 0.20 & 6.0 & 0.14 & 2.0 & 1.36 \\
\hline 8.0 & 0.21 & 16 & 0.67 & 12 & 0.94 & 4.0 & 0.13 \\
\hline \multicolumn{8}{|c|}{ Serum } \\
\hline 2.5 & 1.60 & 3 & 1.28 & 2.5 & 1.10 & 2.5 & 0.49 \\
\hline 5 & 0.83 & 6 & 1.45 & 5 & 1.03 & 5 & 0.87 \\
\hline 10 & 0.99 & 12 & 1.48 & 10 & 1.54 & 10 & 1.77 \\
\hline
\end{tabular}




\subsubsection{Accuracy}

Recovery tests at three concentration levels $(\mathrm{n}=5)$ at isosbestic point for pharmaceutical formulation and human serum were carried out in order to evaluate the accuracy by adding known amount of PRA, DTZ, NAP and MEL to the unknown sample followed by analysis using proposed me- thod. The recovery data ranged from 99.65-100.87, 98.85-100.55, 99.88-101.14 and 98.56-101.40 for PRA, DTZ, NAP and MEL (table 4) showed that the method is suitable for the simultaneous determination of these drugs in pharmaceutical formulation and in human serum.

Table 4. Recovery in pharmaceutical formulations and serum

\begin{tabular}{|c|c|c|c|c|c|c|c|}
\hline Conc & $\% \operatorname{Rec}$ & Conc & $\% \operatorname{Rec}$ & Conc & $\% \operatorname{Rec}$ & Conc & $\% \operatorname{Rec}$ \\
\hline PRA & & DTZ & & NAP & & Mel & \\
\hline \multicolumn{8}{|c|}{ Pharmaceutical formulation } \\
\hline 2.5 & 100.87 & 3 & 100.44 & 2.5 & 98.88 & 2.5 & 101.40 \\
\hline 5 & 99.83 & 6 & 99.85 & 5 & 99.30 & 5 & 100.22 \\
\hline 10 & 99.65 & 12 & 98.85 & 10 & 100.21 & 10 & 99.72 \\
\hline \multicolumn{8}{|c|}{ Serum } \\
\hline 2.5 & 100.57 & 3 & 100.55 & 2.5 & 101.14 & 2.5 & 98.56 \\
\hline 5 & 99.79 & 6 & 99.77 & 5 & 101.48 & 5 & 100.81 \\
\hline 10 & 100.50 & 12 & 99.99 & 10 & 100.84 & 10 & 100.02 \\
\hline
\end{tabular}

\subsubsection{Detection and Quantitation Limits}

Limit of detection and limit of quantitation [43] are the concentration of samples that give peak height three times or ten times to the baseline noise and were found to be 33,70 , 50 and $80 \mathrm{ng} \mathrm{mL}-1$ and 100, 220, 140 and $230 \mathrm{ng} \mathrm{mL}-1$ for PRA, DTZ, NAP and MEL at isosbestic point. The data is presented in table 2 .

\subsubsection{Ruggedness}

The ruggedness was assessed on two different columns Discovery, C18 $(5 \mu \mathrm{m}, 25 \times 0.46 \mathrm{~cm})$ and Purospher STAR, C18 $(5 \mu \mathrm{m}, 25 \times 0.46 \mathrm{~cm})$ on the same instrument by the same analyst. The analytical results were unaffected by change in column parameter and proved to be stable and reliable for everyday analysis (table 5).

Table 5. Robustness and ruggedness

\begin{tabular}{|c|c|c|c|c|c|c|c|c|c|}
\hline \multirow{2}{*}{ Parameters } & & \multicolumn{2}{|l|}{ PRA } & \multicolumn{2}{|l|}{ DTZ } & \multirow[t]{2}{*}{ NAP } & \multicolumn{3}{|c|}{ MEL } \\
\hline & & $\mathbf{N}$ & $\mathbf{T}$ & $\mathbf{N}$ & $\mathbf{T}$ & & $\mathbf{N}$ & $\mathbf{T}$ & $\mathbf{N}$ \\
\hline \multirow{3}{*}{$\mathrm{pH}$} & 3.2 & 4765 & 1.59 & 6079 & 1.73 & 5125 & 1.45 & 6880 & 1.41 \\
\hline & 3.4 & 4873 & 1.71 & 6033 & 1.79 & 5240 & 1.16 & 6484 & 1.38 \\
\hline & 3.6 & 4896 & 1.95 & 5802 & 1.47 & 5292 & 2.00 & 6594 & 1.80 \\
\hline \multirow{3}{*}{$\begin{array}{l}\text { Flow rate } \\
\left(\mathrm{ml} \mathrm{min} \min ^{-1}\right)\end{array}$} & 0.9 & 4712 & - & 5892 & - & 5125 & 1.73 & 6656 & 1.64 \\
\hline & 1.0 & 3560 & - & 4374 & - & 3853 & 2.00 & 4618 & 1.75 \\
\hline & 1.1 & 4923 & 1.92 & 6163 & 1.62 & 5330 & 1.87 & 6740 & 1.61 \\
\hline \multirow{3}{*}{$\begin{array}{l}\text { Mobile phase } \\
\left(\mathrm{MeOH}: \mathrm{H}_{2} \mathrm{O}\right)\end{array}$} & $78: 22$ & 4825 & 1.68 & 6073 & 1.70 & 5065 & 1.29 & 6681 & 1.62 \\
\hline & $80: 20$ & 4810 & - & 6067 & 1.65 & 5350 & - & 6745 & 1.52 \\
\hline & $82: 18$ & 4671 & - & 5917 & - & 5153 & 1.99 & 6550 & 1.20 \\
\hline \multirow{2}{*}{ Column } & Purospher STAR & 4533 & 1.20 & 5988 & 1.65 & 4890 & 1.93 & 6760 & 1.62 \\
\hline & Discovery & 3454 & - & 4360 & 1.53 & 3861 & 1.81 & 4798 & 1.51 \\
\hline
\end{tabular}

$N=$ Theoretical plates, $T=$ Tailing factor

\subsubsection{Robustness}

Minor variations in analytical parameters were introduced and any difference between the results was observed. The method was found to be robust for changes in flow rate from 0.90 to $1.10 \mathrm{~mL}$ min-1, mobile phase composition, methanol-water proportions 78:82, 80:20 and 82:12 and mobile phase $\mathrm{pH}$ in the range of 3.2-3.6. Results indicated that the method is quite suitable and can successfully be applied for routine analysis (table 5).

\subsection{Pharmaceutical Formulations and Serum}

The assay of drugs in serum samples and in pharmaceutical formulation was carried out by preparing the samples as described earlier. The samples of desired concentrations were prepared for serum and pharmaceutical formulation and assayed in triplicates, which showed no significant difference in the results obtained for regression characteristics (table 2), precision (table 3) and recovery (table 4) 
without interference of excipients or serum components, confirming that the method is reliable for everyday analysis in human serum and in pharmaceutical formulation.

\subsection{Comparison of Isosbestic Method with Time Program Method}

The method was compared by programming the detector adjusting the wavelength with time to match the individual analyte's absorption maxima which enhanced sensitivity and linearity range. The LOD values shifted down drastically.

In this respect, the detector was fixed at $237 \mathrm{~nm}$ for $0-3.5$ $\min , 240 \mathrm{~nm}$ for 3.6-4.5 $\mathrm{min}, 230 \mathrm{~nm}$ for 4.6-5.5 min and $205 \mathrm{~nm}$ for 5.6-7.0 min respectively. The respective chromatogram showing the difference in peak height at isosbestic point as well as after programming the detector is presented in figure 5. A drastic change was observed when the sample of same concentration was injected at isosbestic point as well as at time program method. The sensitivity and linear range was enhanced $0.25-8.0,0.5-16,0.4-12$ and 0.2-4.0 $\mu \mathrm{g} \mathrm{mL-1} \mathrm{for} \mathrm{PRA,} \mathrm{DTZ,} \mathrm{NAP} \mathrm{and} \mathrm{MEL} \mathrm{respectively,}$ which is considerably lower than the range established at isosbestic point. The LOD values were also shifted to 15,42 , 20 and $10 \mathrm{ng} \mathrm{mL}-1$ from 33, 70, 50 and $80 \mathrm{ng} \mathrm{mL}-1$ indicating the high sensitivity of method. Moreover, the LOQ values shifted to 46, 128, 70 and $20 \mathrm{ng}$ mL-1 from 100, 220, 140 and $230 \mathrm{ng} \mathrm{mL}-1$ for PRA, DTZ, NAP and MEL respectively. The inter-day and intra-day \%RSD of the method was found to be $0.08-0.75,0.20-1.02,0.14-0.94$ and 0.13-1.00 which is in acceptable limits. Overall, the method was found to be highly sensitive and precise and can conveniently be applied for the analysis of these drugs in human serum and pharmaceutical formulation.

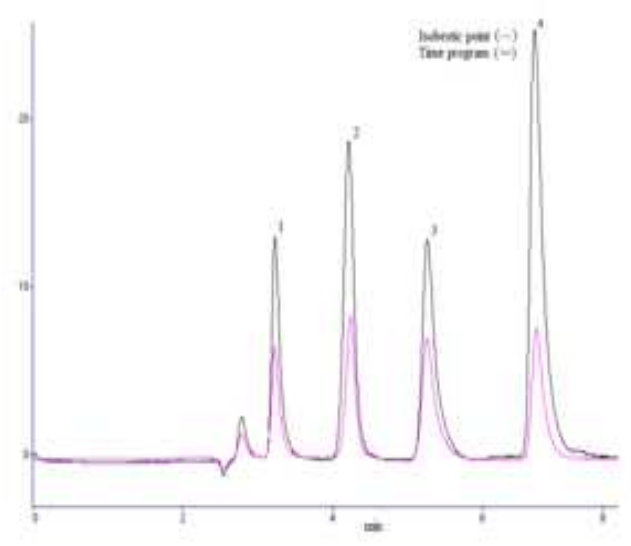

Fig. 5. Comparison of (1) PRA, (2) DTZ (3) NAP and (4) MEL at isosbestic point and time program

\section{4.. Conclusion}

Liquid chromatographic method for the simultaneous determination of PRA, DTZ, NAP and MEL has been developed and validated at isosbestic point of $220 \mathrm{~nm}$ and by programming the detector adjusting the wavelength with time to match the individual analyte's $\lambda \max (237,240,230$ and $205 \mathrm{~nm}$ ); which enhanced the resolution and separation. The method was compared by programming the detector adjusting the wavelength with time to match the individual analyte's chromophore which enhanced sensitivity with linear range of each molecule.

The determination at time program method is advantageous as it gives lesser quantitation limit and requires small sample volume and does not require expensive diode array detector. The method was found to be linear with correlation coefficient greater than 0.998 in each case. The proposed method can be successfully applied for the determination of these drugs with good percent recovery values in human serum and pharmaceutical formulation with out any chromatographic interference from tablet excipients or endogenous components of serum.

\section{Acknowledgement}

Mrs Saeeda Nadir Ali would like to acknowledge Higher Education Commission, Pakistan for providing indigenous scholarship for $\mathrm{Ph} . \mathrm{D}$ research work.

\section{References}

[1] Y. An, H. Xin, W. Yan, X. Zhou, Exp. Toxicol. Pathol. 2011, $63,215$.

[2] G. Mariucci, E. Taha, M. Tantucci, C. Spaccatini, A. Tozzi, M. V. Ambrosini, Eur. J. Pharmacol. 2011, 660, 381.

[3] J. D. Dietz, S. Du, C. W. Bolten, M. A. Payne, C. Xia, J.R. Blinn, J.W. Funder, X. Hu, Hypertension 2008, 51, 742.

[4] V. Andrisano, P. Hrelia, R. Gotti, A. Leoni, V. Cavrini, J. Pharm. Biomed. Anal. 2001, 25, 589.

[5] L. G Lala, P. M. D'Mello, S. R. Naik, J. Pharm. Biomed. Anal. 2002, 29, 539 .

[6] A. G. Gnidec, W. J. Sibbald, H. Cheung, C.A. Metz, J. Appl. Physiol. 1988, 65, 1024.

[7] N. K. S. Khoo, F. P. H. Chan, M. N. Saarloos, P. K. Lala, Clin. Exp. Metastasis. 1992, 10, 239.

[8] T. P Kennedy, N. V Rao, W. Noah, J. R. Michael, J. M. H. Jafri, G. H. Gurtner, J. R. Hoidal, J. Clin. Invest. 1990, 86, 1565.

[9] K. Kircali, M. Tuncel, H. Y. Aboul-Enein, IL Farmaco. 2004, $59,241$.

[10] S. Ashour, H. Nakshbandi, S. Omar, Int. J. Biomed. Sci. 2008, $4,135$.

[11] K. Cai, B. Tan, Z. Feng, Z. Li, M. Huang, X. Zhao, Chin. J. Chromatogr. 1996, 14, 121.

[12] B. G. Chaudhari, N. M. Patel, P. B. Shah, Indian. J. Pharm. Sci. 2007, 69, 130.

[13] I. A. Darwish, A. R. M. Al-Obaid, H. A. Al-Malaq, Talanta. $2009,79,1478$.

[14] M. M. Ayad, A. Shalaby, H. E. Abdellatef, M. M. Hosny, 
Anal. Bioanal. Chem. 2003, 376, 710.

[15] R. I. L. Catarino, A. C. L. Conceição, M. B. Q. Garcia, M. L. S. Goncalves, J. L. F. C. Lima, M. M. Correia dos Santos, J. Pharm. Biomed. Anal. 2003, 33, 571.

[16] N. Sultana, M.S. Arayne, N. Shafi, Pak. J. Pharm. Sci. 2007, 20,279 .

[17] P. V. Devarajan, V. V. Dhavse, J. Chromatogr. B: Biomed. Appl. 1998, 706, 362.

[18] O. Grech-Belanger, E. Leboeuf, S. Langlois, J. Chromatogr. B: Biomed. Appl. 1987, 417, 89.

[19] M. A. Sanchez, F. R. P. Rocha, Anal. Chim. Acta. 2011, 694, 95.

[20] T. M. Phillips, E. F. Wellner, Biomed. Chromatogr. 2006, 20, 662.

[21] A. Aresta, F. Palmisano, C. G. Zambonin, J. Pharm. Biomed. Anal. 2005, 39, 643.

[22] M. H. Guermouche, N. Atik, H. Chader, J. AOAC Int. 2002, $83,1489$.

[23] I. R. Miksa, M. R. Cummings, R. H. Poppenga, J. Anal. Toxicol. 2005, 29, 95 .

[24] N. E. Larsen, K. Marinelli, J. Chromatogr. B: Biomed. Appl. $1981,222,482$

[25] E. A. Taha, N. N. Salama, L. E. S. A. Fattah, Chem. Pharm. Bull. 1981, 54, 653.

[26] A. E. Radi, M. Ghoneim, A. Beltagi, Chem. Pharm. Bull. $2001,49,1257$.

[27] E. M. Hassan, J. Pharm. Biomed. Anal. 2002, 27, 771.

[28] W. R. G. Baeyens, G. Van der Weken, E. D'haeninck, A. M. Garcia-Campana, T. Vankeirsbilck, A. Vercauteren, P. Deprez, J. Pharm. Biomed. Anal. 2003, 32, 839.

[29] S. E. Vignaduzzo, P. M. Castellano, T. S. Kaufman, J. Pharm.
Biomed. Anal. 2008, 46, 219.

[30] Y. H. Hsieh, S. J. Lin, S. H. Chen, J. Sep. Sci. 2006, 29, 1009.

[31] N. Sultana, M. S. Arayne, S. N. Ali, M. H. Zuberi, Med. Chem. Res. 2012, 21, 2443.

[32] M. S. Arayne, N. Sultana, A. Tabassum, S. N. Ali, S. Naveed, Med. Chem. Res. 2012, 21, 4542.

[33] M. S. Arayne, N. Sultana, S. N. Ali, Amer. J. Anal. Chem. 2013, 4, 24

[34] N. Sultana, M. S. Arayne, W. Shahzad, J. Chil. Chem. Soc. 2010, 55, 193.

[35] N. Sultana, M. S. Arayne, N. Safila, Chin. J. Chem. 2011, 29, 1216.

[36] N. Sultana, M. S. Arayne, R. Siddique, N. Safila, Amer. J. Anal. Chem. 2012, 3, 147.

[37] N. Sultana, M. S. Arayne, S. N. Ali, Anal. Bioanal. Techniques. 2013, 3, 154.

[38] M. S. Arayne, N. Sultana, A. Tabassum, Res. Rep. Med. Chem. 2012, 2, 19 .

[39] N. Sultana, M. S. Arayne, N. Safila, F. A. Siddiqui, Chromatographia. 2010, 71, 71 .

[40] M. S. Arayne, N. Sultana, F. A. Siddiqui, Pak. J. Pharm. Sci. 2005, 18, 58.

[41] N. Sultana, M. S. Arayne, B. Iftikhar, J. Chin. Chem. Soc. 2008, 5, 1022.

[42] International Conference of Harmonization of Technical Requirements for Registration of Pharmaceuticals for Human Use, ICH Harmonized Tripartite Guideline, Validation of Analytical Procedure: Text and Methodology Q2 (R1) Complimentary Guideline on Methodology Dated 06 Nov 1996, Incorporated in Nov 2005, London.

[43] D. A. Armbruster, M. D. Tillman, L. M. Hubbs, Clin. J. Chem. 1994, 40, 1233. 